\title{
Anticipating Common-Mode Conducted Emission of DC-DC Converter from Electric Near-Field Scan
}

\author{
A. Boyer, N. Nolhier, F. Caignet, S. Ben Dhia \\ LAAS-CNRS \\ Univ. de Toulouse, INSA, UPS, LAAS \\ Toulouse, France

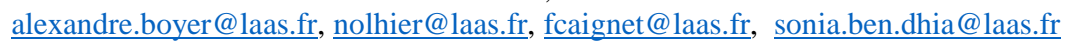

\begin{abstract}
This paper aims at proposing a method based on electric near-field measurement to estimate common-mode conducted emission produced by DC-DC converter along a cable harness. The method is evaluated on two case studies: an academic board with simple rectangular copper island and buck converter board.
\end{abstract}

Keywords-Near-field scan, common-mode current, conducted emission.

\section{INTRODUCTION}

Sniffing electric or magnetic field in the vicinity of electronic components with near-field probes is a well-known practical method to diagnose EMC problems. Near-field scan (NFS) is the sophisticated version of near-field sniffing to reconstruct map of the quantitative distribution of electric and magnetic fields [1]. NFS is considered as a powerful method to identify root-cause of EMC problems at printed-circuit board (PCB) or integrated circuit (IC) level, as demonstrated in numerous publications. For example, it was used for the characterization of emission at PCB [2] and IC level [3] [4], risk of near-field coupling above toroidal inductance [5] [6], HF current reconstruction [7], RF [8] and ESD immunity [9] [10].

NFS does not constitute an EMC certification method, but an investigation and a prequalification method, mainly applicable at PCB level. To this end, in order to fulfill completely the needs of electronic board designers, NFS should deliver an estimation of EMC level, even with a reasonable uncertainty. Such a result would be a great benefit for them to evaluate if a prototype should pass or not EMC tests, and identify possible origins of problems.

Except methods to predict radiated emission of PCB from magnetic NFS, based either on near-field to far-field transformation or equivalent dipole identification [11] [12], few works have been done to estimate EMC level from NFS. For example, let consider EMC issues related to DC-DC converter, which is one of the main contributors of EMC problems in electronic equipments. Magnetic NFS is often used to locate source of electromagnetic emission of DC-DC converter [13]. One major issue is related to conducted emission (CE) along cable harness that produces radiated emission. No processing methods of the NFS results have been developed to help designer to estimate CE and anticipate possible risks of non-compliance.

This paper aims at proposing and evaluating a method based on NFS measurement to estimate CE produced by DCDC converter along a cable harness. Compared to previous works related to NFS and DC-DC converter which were based exclusively on measurement of magnetic field, the proposed approach uses electric field measurement. This choice is justified by the major contribution of the switching node of

This work is supported by the Nanoscan project (CNES N ${ }^{\circ}$ 200111/00) sponsored by Centre National d'Etudes Spatiales (CNES).
DC-DC converter to common-mode emission. Due to the strong voltage fluctuation that affects this node, it produces an intense local electric field that can contribute to commonmode emission. This contribution cannot be characterized by measurement of near magnetic field.

Common-mode current propagation along cable harness is usually characterized by a current clamp, which constitutes a practical and accurate measurement method. The paper attempts to correlate common-mode CE measured by a current clamp and electric NFS. It does not aim at proposing an alternative to current clamp measurement, but proposing a predictive method of the common-mode emission produced by a PCB that can be used at board analysis level. Two validation cases are proposed: in a first academic test board, simple rectangular copper islands have been designed to verify in which extents common-mode current and electric near-field are correlated. In a second board, a buck converter has been designed to compare the measured and the estimated common-mode current based on our approach. The paper is organized as follows: the proposed approach is presented in section II. The case studies and the experimental set-up are described in section III. In the fourth section, measurement results of electric NFS and common-mode current are compared on the simple structure, in order to verify the existence of a correlation and explain its origin. In the fifth section, the same approach is used on the DC-DC converter board.

\section{PRESENTATION OF THE APPROACH}

The purpose is to estimate the CE produced by a DC-DC converter along a cable harness during a typical EMC test. More specifically, the common-mode current is considered. It is particularly important since it is a major contributor to radiated emission. The analysis of the electronic architecture of DC-DC converter shows that one of the main sources of common-mode emission produced by the DC-DC converter board is related to the switch node. As illustrated on Fig. 1, which presents the typical structure of an asynchronous buck DC-DC converter. The switching node (SW) is affected by a high dv/dt which results on a strong electric field locally [14]. In Fig. 13, an example of electric NFS will be presented, which illustrates the strong electric field produced in the close vicinity of the $\mathrm{SW}$ node.

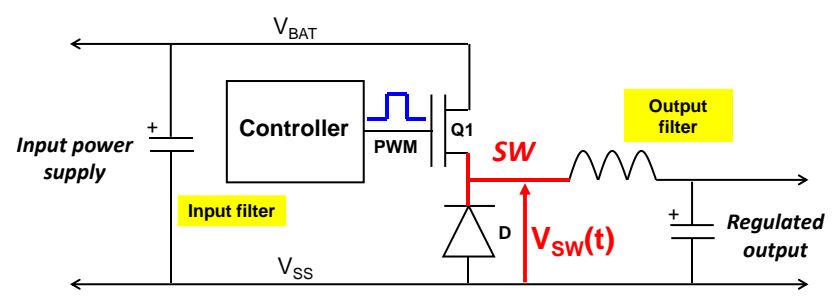


Fig. 1. Example of typical structure of a DC-DC converter (here an asynchronous buck converter)

This node constitutes an electric-field antenna which produces displacement current that couples on nearby structures and results in common-mode current circulation along power supply cable of the DC-DC converter. For example, Fig 2 illustrates a DC-DC converter mounted on a PCB and placed above a metallic chassis. The periodical switching voltage $V_{S W}(t)$ between nearly $V_{B A T}$ and $V_{S S}$ results in a local intense electric field. A part of the electric field line produced by the SW node couples to the chassis and contributes to the generation of common-mode current along the power supply cable. Another source of conducted emission is the radiation produced by the board itself. This source becomes significant when its size or its height to the chassis exceed one tenth of the wavelength. If typical dimensions of electronic boards are considered (less than some tens of centimeters), it happens above $300 \mathrm{MHz}$. Typically, spectral content of DC-DC converter is located below some hundreds of $\mathrm{MHz}$, so this source of commonmode emission is neglected in this paper.

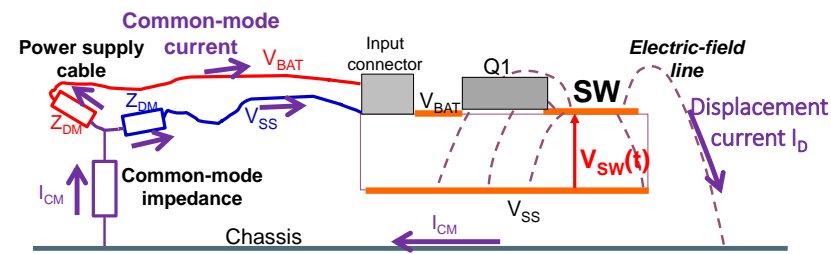

Fig. 2. Generation of common-mode current due to DC-DC converter switching

Locally, the displacement current density $J_{D}$ is related to the electric field $E$ according to (1) where $\varepsilon_{0}$ is the dielectric permittivity. In harmonic regime, if the electric-field that crosses a given surface $\mathrm{S}$ is measured, an equivalent current $I_{D}$ can be determined (2).

$$
\begin{gathered}
\overrightarrow{J_{D}}=\varepsilon_{0} \frac{d \vec{E}}{d t} \\
I_{D}=j \varepsilon_{0} \omega \iint_{S} \vec{E} \cdot \overrightarrow{d S}
\end{gathered}
$$

It is not straightforward to determine in which proportion this displacement current will couple to the DC-DC converter board (resulting in differential-mode current) or couple to nearby structures and result in common-mode current. This proportion depends on the DC-DC converter design and installation. However, it should remain nearly constant for a given PCB format and installation on an EMC test bench.

The purpose of the paper is to verify that the commonmode current measured on the power supply cable harness of a DC-DC converter is correlated to the displacement current determined by the characterization of the electric field in the near-field region of the DC-DC converter. In order to verify it and estimate the proportion of displacement current that contributes to common-mode current, several test boards have been designed. They contain either a DC-DC converter or a simple copper island that simulates the effect of the switching node of a DC-DC converter. These test boards and the proposed experimental set-up are detailed in the next part.

\section{DESCRIPTION OF THE SET-UP}

\section{A. Presentation of the Case Studies}

\section{1) Buck converter board}

On a first test board, an asynchronous buck converter has been designed. It is mounted on a 100x100 mm four-layer board. All the components are mounted on the top layer and a full ground plane is inserted on an internal layer. A simplified electric diagram of the converter is presented in Fig. 3. The position of the switching node is indicated by the symbol $S W$. It is based on the step-down voltage regulator LM22677 provided by Texas Instruments. It is configured to convert 12 $\mathrm{V}$ to $5 \mathrm{~V}$ with a maximum current of $5 \mathrm{~A}$. The switching frequency is set to $1.37 \mathrm{MHz}$. During the test, The DC-DC converter is powered by a battery through a $1.2 \mathrm{~m}$ long bifilar pair cable and a $2.2 \Omega$ dummy load is connected to its output.

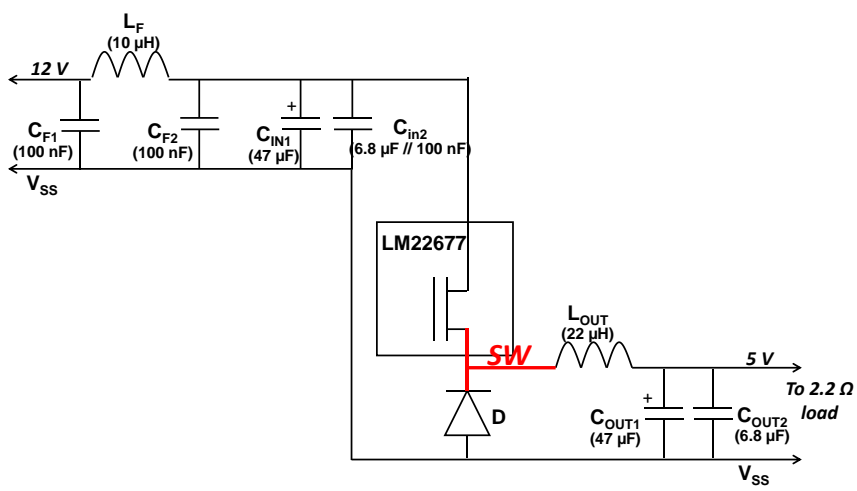

Fig. 3. Electrical diagram of the studied buck converter

\section{2) Island board}

In order to study the common-mode current produced by the switching node of the buck converter, several rectangular copper islands have been designed on 100x100 mm two or four-layer boards. They are all routed on the top layer of the board and above a full ground plane. They differ in size, height to the ground plane and position on the board. In this paper, four structures are considered. Their characteristics are summarized in Table I. P1 and P2 are routed on a four-layer board while $\mathrm{P} 3$ and $\mathrm{P} 4$ are routed on a two-layer board. P4 is the only island routed close to the PCB edge so that a larger common-mode emission can be expected. These islands are opened electrically. Their equivalent capacitance has also been measured with a VNA (Table I). They are excited by a sine waveform produced by an external RF synthesizer through a coaxial connector. During the test, the RF power is kept constant and equal to $14 \mathrm{dBm}$.

\section{TABLE I. TESTED ISLAND STRUCTURES}

\begin{tabular}{|l|c|c|c|c|}
\hline Name & $\begin{array}{c}\text { Size } \\
(\mathbf{m m})\end{array}$ & $\begin{array}{c}\text { Height to the } \\
\text { ground plane }\end{array}$ & $\begin{array}{c}\text { Distance to } \\
\text { board edge }\end{array}$ & $\begin{array}{c}\text { Capacitance } \\
\text { (pF) }\end{array}$ \\
\hline P1 & $10 \times 10$ & $0.32 \mathrm{~mm}$ & $25 \mathrm{~mm}$ & 12.2 \\
\hline P2 & $25 \times 25$ & $0.32 \mathrm{~mm}$ & $20 \mathrm{~mm}$ & 67.4 \\
\hline P3 & $10 \times 10$ & $1.6 \mathrm{~mm}$ & $30 \mathrm{~mm}$ & 3.9 \\
\hline P4 & $10 \times 10$ & $1.6 \mathrm{~mm}$ & $1 \mathrm{~mm}$ & 1.2 \\
\hline
\end{tabular}

\section{B. Experimental set-up}

Two different test benches are used. Firstly, an automated near-field scanner is used to produce near-field map at constant height above the board under test. A calibrated 
electric field probe (model Langer XF-E-04s) is positioned and moved with a precision of $50 \mu \mathrm{m}$ above the board under test. This probe senses the vertical component of the electric field. However, this test bench is not adapted to CE test as recommended by typical EMC standard tests, which require tests above a large conductive reference plane within a semianechoic chamber. That's why CE tests are done in this type of test environment (Fig. 4). Common-mode current along the cable harness is measured by a current clamp placed at $20 \mathrm{~cm}$ of the board under test. The cable is mounted at $50 \mathrm{~mm}$ above the reference plane and is terminated by a $(50 \mu \mathrm{H}+5 \Omega) / / 50 \Omega$ LISN. The common-mode current that circulates on the cable is affected by the installation of the board and the test bench. In order to control the electric near-field produced by the test board during CE test, the board under test is mounted on a non-conductive three-axis manual positioner to place the electric-field probe. Thus, a comparison between commonmode current and electric near-field spectra can be done exactly in the same condition, without any changes of the common-mode impedance. All the measurements are done in frequency domain with a spectrum analyzer, between $1 \mathrm{MHz}$ and $300 \mathrm{MHz}$.

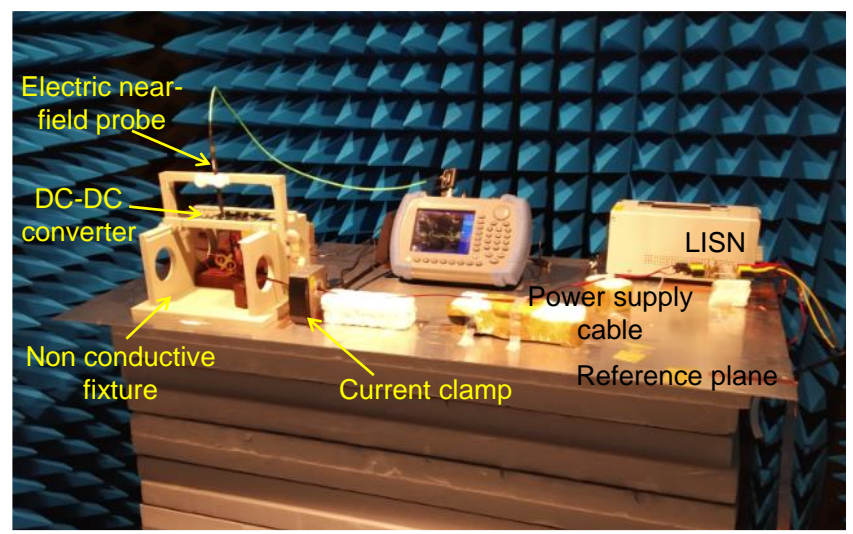

Fig. 4. Experimental set-up

\section{MEASUREMENT RESULTS OF ISLAND BOARD}

\section{A. Electric Field Scan Measurement}

The electric-field is measured at $10 \mathrm{~mm}$ above the surface of the test board and is repeated for different excitation frequencies. A strong electric field spot is localized just above the copper island and tends to decrease rapidly with the distance. Fig. 5 shows the electric near-field map above island $\mathrm{P} 1$ measured at $10 \mathrm{MHz}$. The spatial distribution of the electric field remains unchanged whatever the frequency, at least up to $300 \mathrm{MHz}$. Fig. 6 shows the evolution vs. excitation frequency of the electric field measured at the vertical of the island center, for the four tested islands. While the copper island is electrically small, the quasi-static approximation is valid. If the ground plane is supposed to be infinitely large and if the effect of air-dielectric interface is neglected, the normal electric field $E_{Z}$ at a distance $R$ above the center of island can be computed according to (3), where $W$ and $L$ are the width and length of the island, $h$ the height to the ground plane, $C$ the equivalent capacitance of the island and $V$ the excitation voltage. The difference of electric field measured above the different islands can be understood from this model.

$$
\begin{aligned}
E_{Z}=\frac{C . V}{\pi \varepsilon_{0} W \cdot L} & {\left[\operatorname{atan}\left(\frac{W \cdot L}{4 R \sqrt{\left(\frac{W}{2}\right)^{2}+\left(\frac{L}{2}\right)^{2}+R^{2}}}\right)-\right.} \\
& \left.\operatorname{atan}\left(\frac{W \cdot L}{4(R+2 h) \sqrt{\left(\frac{W}{2}\right)^{2}+\left(\frac{L}{2}\right)^{2}+(R+2 h)^{2}}}\right)\right]
\end{aligned}
$$

Up to some tens of $\mathrm{MHz}$, the electric field above the islands is quite constant. The highest electric field is measured above $\mathrm{P} 2$ since it is the largest island. Although P2, P3 and P4 have the same surface, the electric field above P3 and P4 is higher than $\mathrm{P} 1$ because the height to the ground plane is larger. Above $60 \mathrm{MHz}$, the electric field above P2 decreases with a rate of $-20 \mathrm{~dB} / \mathrm{dec}$, because the internal resistance of the RF synthesizer and the capacitance of the island forms a low-pass filter.

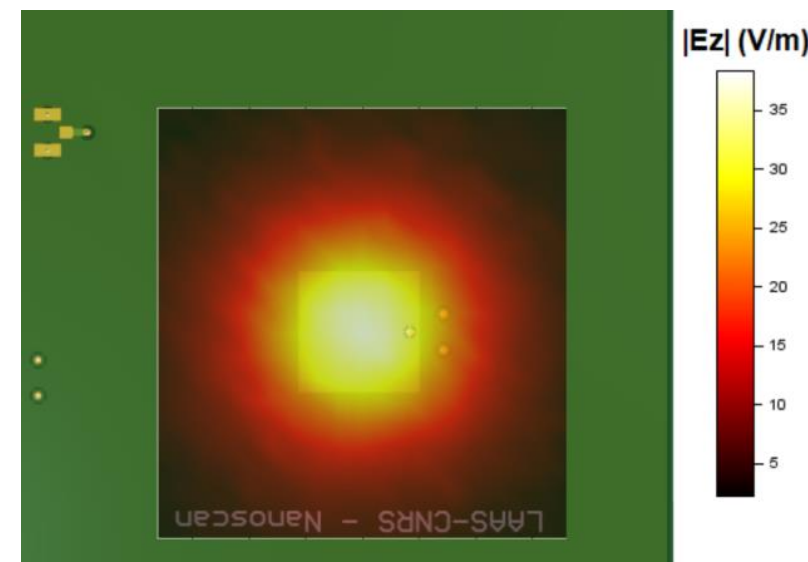

Fig. 5. Electrical near-field map at $10 \mathrm{~mm}$ above island P1 (excitation frequency $=10 \mathrm{MHz}$ )

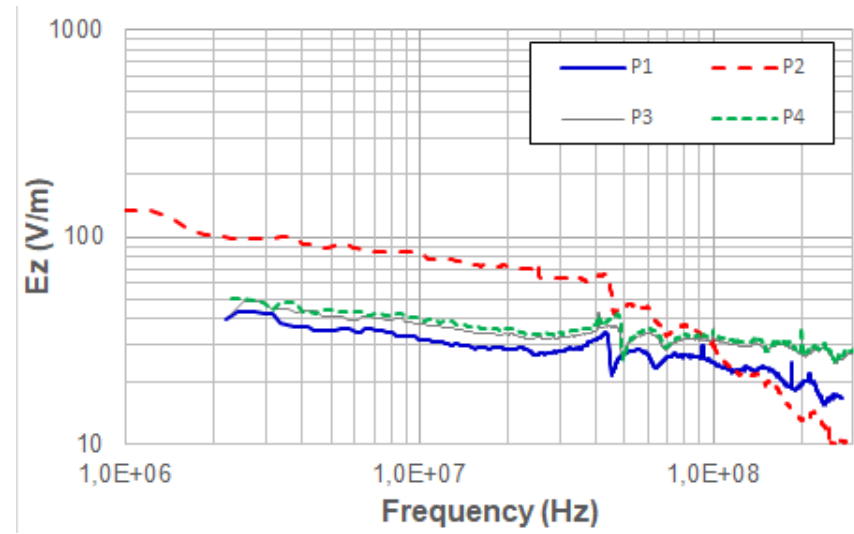

Fig. 6. Evolution vs. frequency of the electric-field measured at $10 \mathrm{~mm}$ above the center of the tested copper islands

From the NFS map, the total displacement current that crosses the scan surface is estimated according to (2) and its frequency evolution for the four copper islands is plotted in Fig. 7. Up to some tens of $\mathrm{MHz}$, the displacement current increases at nearly $20 \mathrm{~dB} / \mathrm{dec}$. Compared to the displacement current produced by $\mathrm{P} 1$ at $10 \mathrm{MHz}$, the displacement currents produced by $\mathrm{P} 2, \mathrm{P} 3$ and $\mathrm{P} 4$ are respectively $13 \mathrm{~dB}, 3.4$ and 5.6 $\mathrm{dB}$ larger. Although $\mathrm{P} 3$ and $\mathrm{P} 4$ have the same geometrical dimensions, P4 produces a larger displacement current because the electric field decreases more slightly on the board edge. 


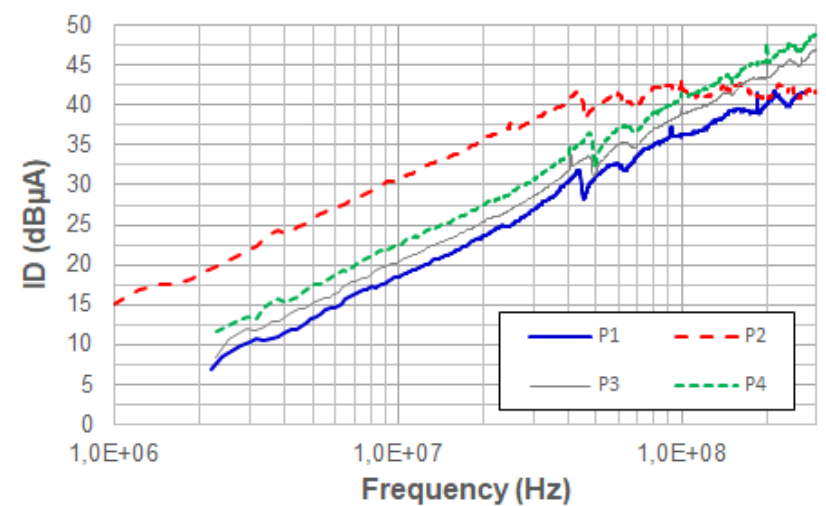

Fig. 7. Evolution vs. frequency of the estimated displacement current measured at $10 \mathrm{~mm}$ above the center of the tested copper islands

One interesting observation can be realized if the probe is placed at a very short distance to the board (e.g. $1 \mathrm{~mm}$ ) and far away from the copper island. Beyond $30 \mathrm{MHz}$, a weak but constantly distributed electric field can be measured above the ground plane of the board whatever the measurement point position. This result proves that the board ground plane is affected by a common-mode voltage fluctuation, that can also result in displacement current generation. Fig. 8 presents the frequency evolution of the electric field measured a $1 \mathrm{~mm}$ above the ground plane of the board, when P1, P2, P3 or P4 are excited. The estimation of the displacement current is plotted in Fig. 9.

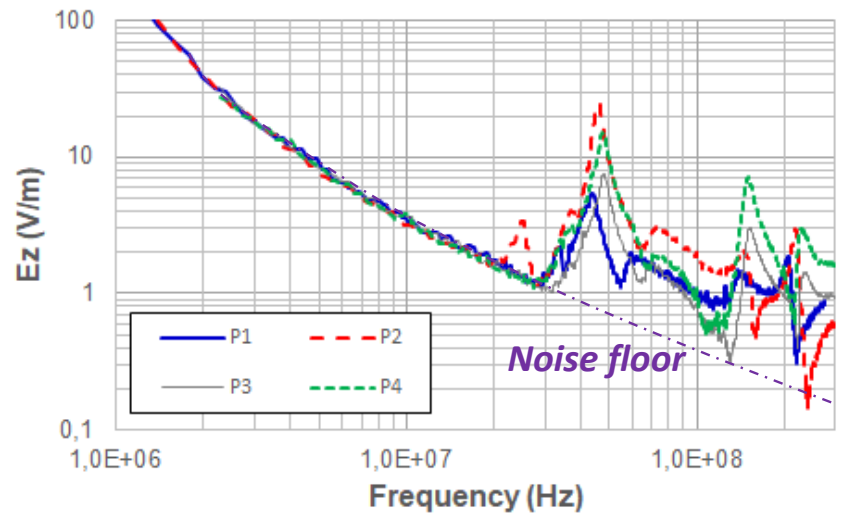

Fig. 8. Evolution vs. frequency of the electric-field measured at $1 \mathrm{~mm}$ above the ground plane of the island board

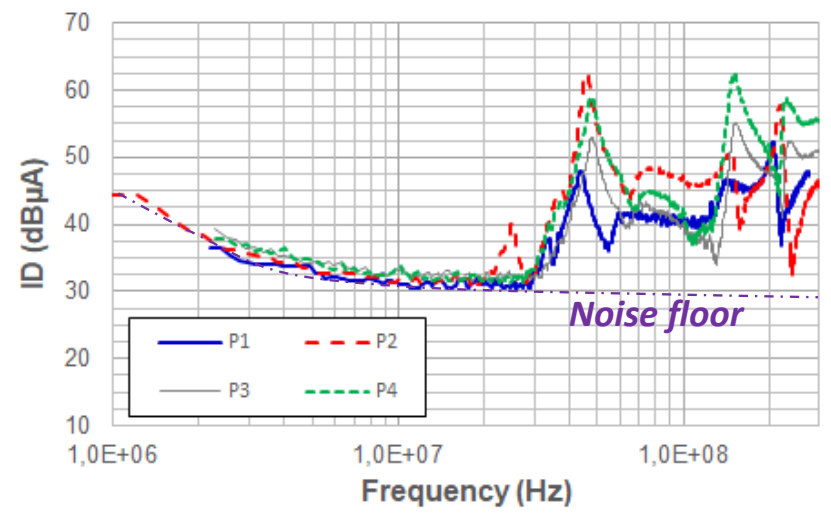

Fig. 9. Evolution vs. frequency of the estimated displacement current measured at $1 \mathrm{~mm}$ above the ground plane of the island board

\section{B. Common-Mode Current Measurement}

The common-mode current measured along the RF excitation cable is presented in Fig. 10. It increases linearly with frequency up to $30 \mathrm{MHz}$. The largest amount of common-mode current is produced by $\mathrm{P} 2$, followed by $\mathrm{P} 4, \mathrm{P} 3$ and finally P1. At $10 \mathrm{MHz}$, the gaps between common-mode current measured on $\mathrm{P} 2, \mathrm{P} 3$ and $\mathrm{P} 4$ compared to $\mathrm{P} 1$ are respectively equal to $12.5 \mathrm{~dB}, 1.7$ and $4.2 \mathrm{~dB}$ larger. These gaps are similar to those measured between displacement current above the copper island. A strong resonance is visible around $45 \mathrm{MHz}$, at nearly the same frequencies than the first resonance observed on the estimated displacement current from the ground plane. This resonance varies slightly with the position of the current clamp along the cable, contrarily to the frequency response observed at larger frequency.

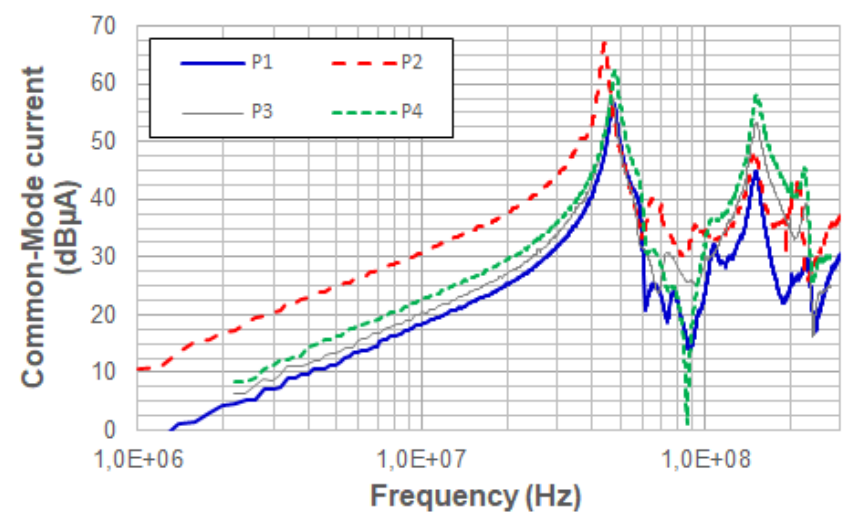

Fig. 10. Evolution vs. frequency of the common-mode current measured on the RF cable of the island board

\section{Correlation between Common-Mode Current and Electric Near-Field}

In order to compare efficiently the evolutions of the common-mode current and the displacement current estimated from electric NFS, these different curves are superimposed in Fig. 11. Two frequency regions can be distinguished. Up to $20 \mathrm{MHz}$, the common-mode current follows exactly the same evolution of the estimated displacement current produced by the copper island. The gap between the common-mode current curves and displacement current is less than $2 \mathrm{~dB}$ and can be explained by the difference of measurement sensitivity and equipment calibration errors. It proves that the voltage fluctuation of the copper island is the dominant mechanism of the generation of common-mode current. Whatever the tested island, it can be noticed in the range 1 to $10 \mathrm{MHz}$ that there is a gap nearly equal to $0 \mathrm{~dB}$ between the measured common-mode current and the estimated displacement current. It means that nearly all the displacement current produced by the copper island couples to the board ground plane. This proportion may change with the board dimension and installation configuration. This point should be investigated further to confirm it.

Above $20 \mathrm{MHz}$, the displacement current above the switching node is not the only mechanism of common-mode current generation, since the displacement current measured above the ground plane is in the same order. Multiple resonances affect both common-mode current and displacement current above the ground plane. These frequencies are often correlated, especially those around 45 $\mathrm{MHz}$ and $150 \mathrm{MHz}$. The correlation of common-mode current and estimated displacement currents is not perfect. On some frequency ranges, the displacement current is far larger than the common-mode current. This current results from the superposition of both displacement current sources. They cannot be added due to phase difference and the influence of 
current clamp position. However, it can be noticed that the worst-case level of common-mode current can be estimated by the sum of both displacement currents. From an EMC compliance point of view, that information is of major importance.
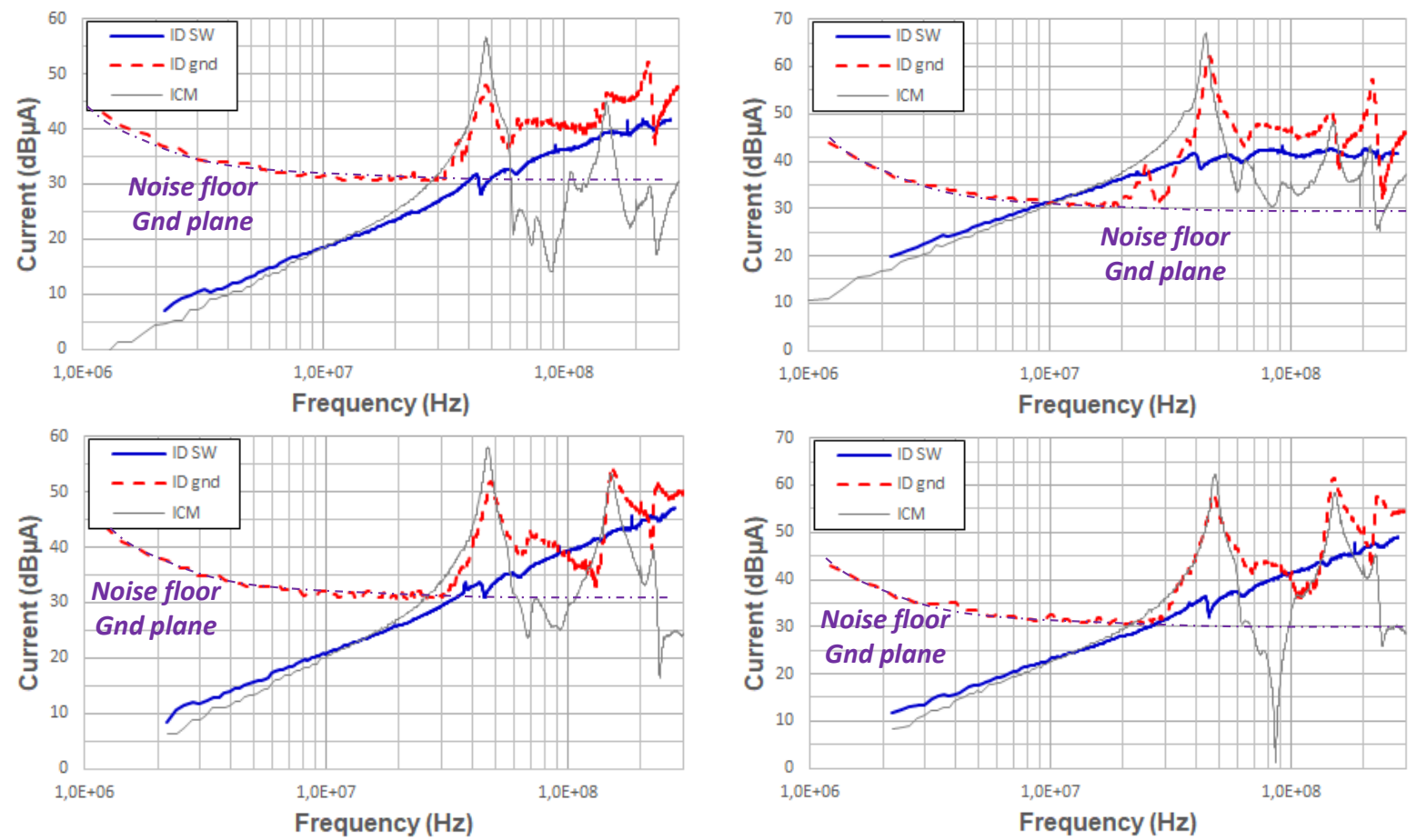

Fig. 11. Comparison between the measured common-mode current (ICM) and the estimated displacement current measured above the island (ID SW) and the ground plane (ID gnd): P1 (top left), P2 (top right), P3 (bottom left), P4 (bottom right)

\section{RESUltS ON BUCK CONVERTER BOARD}

The same measurement procedure is applied on the buck converter board. Fig. 12 presents the common-mode current spectrum measured on the power supply cable. It is nearly constant up to $30 \mathrm{MHz}$, and it is affected by numerous resonances between 30 and $200 \mathrm{MHz}$. Above $200 \mathrm{MHz}$, the common-mode current becomes negligible.

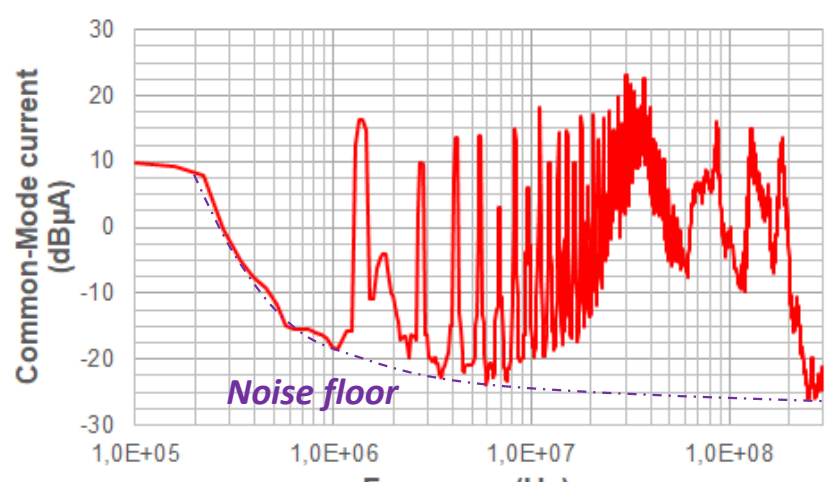

Frequency $(\mathrm{Hz})$

Fig. 12. Common-mode current measured on the buck converter power supply cable

Fig. 13 presents the typical spatial distribution of the electric field at $10 \mathrm{~mm}$ above the buck converter (here at the fundamental frequency). An intense field spot is visible above the switching node of the buck converter. As in the island board case, a weak but constantly distributed electric field can be measured above the ground plane. The frequency spectra of the estimated displacement current are plotted in Fig. 14. The spectrum of the displacement current measured above the switching node (SW) is quite constant up to $120 \mathrm{MHz}$, while the displacement current measured above the ground plane is affected by numerous resonances, especially around $30 \mathrm{MHz}$. This displacement current source is negligible below $6 \mathrm{MHz}$ and above $200 \mathrm{MHz}$.

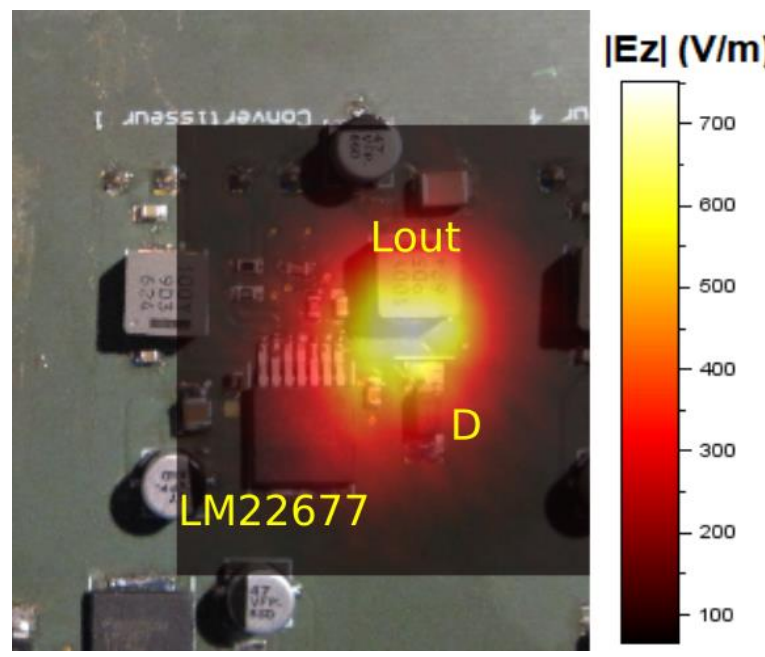

Fig. 13. Electrical near-field map at $10 \mathrm{~mm}$ above the buck converter $(\mathrm{F}=$ $1.372 \mathrm{MHz}$ ) 


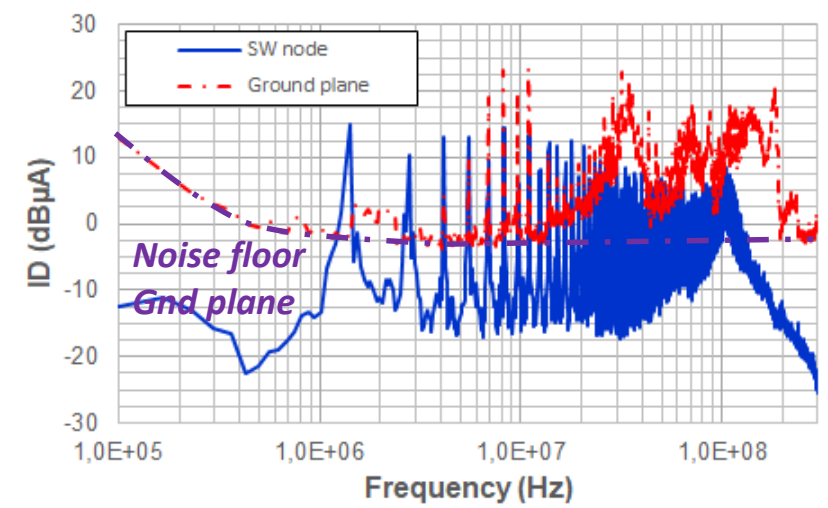

Fig. 14. Estimated displacement current spectra produced by the switch node and ground plane of the buck converter

Based on the observation made with the island board, an estimation of the common-mode current is done from the displacement current measurement. The displacement current from the ground plane is added to the displacement current from the switching node. Moreover, the displacement current from the ground plane is omitted below $4 \mathrm{MHz}$, as it is below the measurement noise floor. Fig. 15 presents the comparison between the measurement and the estimation of the commonmode current. The estimation is quite precise between 1.37 $\mathrm{MHz}$ and $5 \mathrm{MHz}$, and 12 and $50 \mathrm{MHz}$. On the other frequency range, the estimation exceeds the maximum level of the measurement results of less than $10 \mathrm{~dB}$. The influence of the displacement current produced by the ground plane seems to be slightly overestimated. However, the amplitude order is preserved and the estimation predicts that the common-mode current is insignificant above $200 \mathrm{MHz}$. This result tends to prove that electric NFS measurement and processing can provide a worst-case estimation of the common-mode current that circulates along the power supply cable of a DC-DC converter.

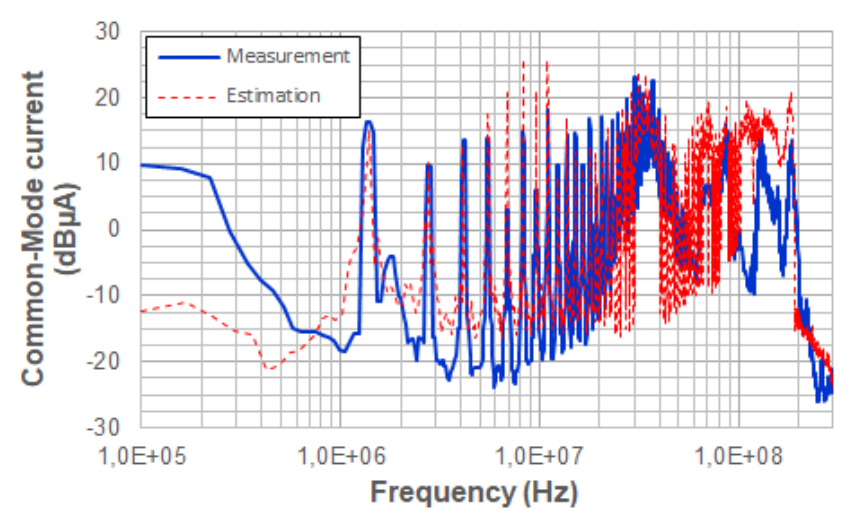

Fig. 15. Comparison between the common-mode current produced by the buck converter and its estimation from electric near-field scan

\section{CONCLUSION}

This paper has presented an approach to estimate the common-mode conducted emission produced by a DC-DC converter, which is one of the main sources of radiated emission. The approach is based on electric near-field measurement at board level. The paper proves that it does not provide only a detection of emission source, but also an estimation of the level that would be measured in a standard conducted emission test. It builds up the interest of near-field scan as an EMC prequalification tool at board prototype level.
The results presented in this paper are promising, but need to be confirmed on other case studies. Tests have been done on PCB not mounted within cabinet, where near-field scan cannot be done. Further works have to be led to verify in which extent the electric-field measured above a PCB outside its cabinet is correlated to the conducted emission. Finally, our approach relies on the assumption that a large proportion of the displacement current produced by the board under test contributed to the common-mode current that circulates along a cable. A methodology to estimate this proportion from basic information about board dimensions and installation should be developed to consolidate this approach.

\section{ACKNOWLEDGMENT}

The authors would like to thank Sarah Sufyar and Christian Elisabelar (CNES) for their valuable support and advises. They also thank Michel Dedier and Bernard Saint Germain for the technical development of the non-conductive support.

\section{REFERENCES}

[1] IEC 61967-3, TS, Ed.1: Integrated circuits- Measurement of electromagnetic emissions, $150 \mathrm{KHz}$ to $1 \mathrm{GHz}$ - Part 3: Measurement of radiated emissions - Surface scan method.

[2] S. Criel, K. Haelvoet, L. Martens, D. De Zutter, A. Franchois, R. De Smedt, P. De Langhe, "Theoretical and experimental quantitative characterization of the near-fields of printed circuit board interconnection structures”, 1995 Int. Symp. On EMC, 14-18 Aug. 1995, Silicon Valley, CA, USA.

[3] C. Labussière-Dorgan, S. Ben Dhia, E. Sicard, J. Tao, H. J. Quaresma, C. Lochot, B. Vrignon, "Modeling the Electromagnetic Emission of a Microcontroller Using a Single Model”, IEEE Trans. On EMC, vol. 50, no. 1, Feb 2008.

[4] X. Dong, S. Deng, T. Hubing, D. Beetner, "Analysis of chip-level EMI using near-field magnetic scanning”, 2004 Int. Symp. On EMC, 9-13 Aug. 2004, Silicon Valley, CA, USA.

[5] P. E. Lévy, C. Gautier, F. Costa, B. Revol, C. Labarre, « Accurate Modelling of Radiated Electromagnetic Field by a Coil with a Toroidal Ferromagnetic Core », IEEE Trans on EMC, vol. 55, no. 5, Oct 2013.

[6] B. Zhang, S. Wang, "Analysis and Reduction of the Near Magnetic Field Emission from Toroidal Inductors", IEEE Trans. On Power Electronics, vol. 35, no. 6, June 2020.

[7] H. Weng, D. G. Beetner, R. E. DuBroff, J. Shi, "Estimation of Current From Near-Field Measurement”, 2005 Int. Symp. On EMC, 8-12 Aug. 2005, Chicago, USA.

[8] A. Boyer, E. Sicard, S. Ben Dhia, "Characterisation of electromagnetic susceptibility of integrated circuits using near-field scan”, Electronic Letters, vol. 43, no. 1, Jan 2007.

[9] G. Muchaidze, J. Koo, Q. Cai, T. Li, L. Han, A. Martwick, K. Wang, J. Min, J.L. Drewniak, D. Pommerenke, "Susceptibility Scanning as a Failure Analysis Tool for System-Level Electrostatic Discharge", IEEE Trans. on EMC, vol. 50, No.2, May 2008.

[10] F. Caignet, N. Nolhier, M. Bafleur, "Dynamic system level ESD current measurement using magnetic field probe", 2015 Asia-Pacific Symp. On EMC, 26-29 May 2015, Taipei, Taïwan.

[11] D. Baudry, M. Kadi, Z. Riah, C. Arcambal, Y. Vives-Gilabert, A. Louis, B. Mazari, "Plane wave spectrum theory applied to near field measurements for electromagnetic compatibility investigations", IET Sci. Meas. Technol., vol. 3, no. 1, 2009.

[12] Y. Vives-Gilabert, C. Arcambal, A. Louis, F. De Daran, P. Eudeline, B. Mazari, "Modeling magnetic radiations of electronic circuits using nearfield scanning method," IEEE Trans. On EMC vol. 49, no. 2, pp. 391-400, May 2007.

[13] K. W. Kam, D. Pommerenke, C. W. Lam, R. Steinfeld, "EMI analysis methods for synchronous buck converter EMI root cause analysis", 2008 Int. Symp. On EMC, 18-22 Aug. 2008, Detroit, USA.

[14] A. Bhargava, D. Pommerenke, K. W. Kam, F. Centola, C. W. Lam, "DC-DC Buck Converter EMI Reduction Using PCB Layout Modification", IEEE. Trans on EMC, vol. 53, no. 3, Aug 2011. 